\title{
Species distribution and introgressive hybridization of two Avicennia species from the Western Hemisphere unveiled by phylogeographic patterns
}

\author{
Gustavo M Mori ${ }^{1}$, Maria I Zucchi ${ }^{2}$, Iracilda Sampaio ${ }^{3}$ and Anete P Souza ${ }^{1,4^{*}}$
}

\begin{abstract}
Background: Mangrove plants grow in the intertidal zone in tropical and subtropical regions worldwide. The global latitudinal distribution of the mangrove is mainly influenced by climatic and oceanographic features. Because of current climate changes, poleward range expansions have been reported for the major biogeographic regions of mangrove forests in the Western and Eastern Hemispheres. There is evidence that mangrove forests also responded similarly after the last glaciation by expanding their ranges. In this context, the use of genetic tools is an informative approach for understanding how historical processes and factors impact the distribution of mangrove species. We investigated the phylogeographic patterns of two Avicennia species, A. germinans and A. schaueriana, from the Western Hemisphere using nuclear and chloroplast DNA markers.

Results: Our results indicate that, although Avicennia bicolor, A. germinans and A. schaueriana are independent lineages, hybridization between A. schaueriana and A. germinans is a relevant evolutionary process. Our findings also reinforce the role of long-distance dispersal in widespread mangrove species such as $A$. germinans, for which we observed signs of transatlantic dispersal, a process that has, most likely, contributed to the breadth of the distribution of A. germinans. However, along the southern coast of South America, A. schaueriana is the only representative of the genus. The distribution patterns of $A$. germinans and $A$. schaueriana are explained by their different responses to past climate changes and by the unequal historical effectiveness of relative gene flow by propagules and pollen.

Conclusions: We observed that A. bicolor, A. germinans and A. schaueriana are three evolutionary lineages that present historical and ongoing hybridization on the American continent. We also inferred a new evidence of transatlantic dispersal for A. germinans, which may have contributed to its widespread distribution. Despite the generally wider distribution of A. germinans, only A. schaueriana is found in southern South America, which may be explained by the different demographic histories of these two species and the larger proportion of gene flow produced by propagules rather than pollen in A. schaueriana. These results highlight that these species responded in different ways to past events, indicating that such differences may also occur in the currently changing world.
\end{abstract}

Keywords: Phylogeography, Introgression, cpDNA, nDNA, Transoceanic dispersal

\footnotetext{
* Correspondence: anete@unicamp.br

${ }^{1}$ Centro de Biologia Molecular e Engenharia Genética, Universidade Estadual

de Campinas, CEP 13083-875, CP 6010 Campinas, São Paulo, Brazil

${ }^{4}$ Departamento de Biologia Vegetal, Instituto de Biologia, Universidade

Estadual de Campinas, CEP 13083-862, Campinas, São Paulo, Brazil

Full list of author information is available at the end of the article
} 


\section{Background}

Mangrove forests are unique tree communities that occupy narrow elevation ranges within the intertidal zones of tropical and subtropical regions. Compared with tropical and subtropical terrestrial plant communities, the few species that occupy these forests are characterized by physiological and ecological traits that make them highly adapted to the coastal environment [1]. The latitudinal distribution of these organisms is mainly determined by both climatic and oceanographic features, including the occurrence of frosts, air and sea surface temperature, precipitation and a suitable intertidal habitat [2-6]. In the context of recent global climate change, there is evidence that these species are currently expanding their geographic distributions poleward within the two major mangrove biogeographic regions: the Atlantic Caribbean East-Pacific region (ACEP) [5,7-10] and the Indo West-Pacific region (IWP) [11-14]. As would be expected from this evidence of current expansion, palynological and stratigraphic data indicate that in the recent past (from the late Holocene and Pleistocene), climatic alterations influenced the worldwide distribution of mangroves $[6,15,16]$. The use of genetic data is an interesting approach to complement the palynologic and stratigraphic methods and to shed light on how the distribution of mangrove trees has changed over time and space.

In the ACEP region, for example, Rhizophora mangle L. (Rhizophoraceae) has expanded its distribution southward along the Brazilian coast since the last glacial maximum (LGM) [17]. Furthermore, evidence shows that in the northern part of the ACEP biogeographic region, Avicennia germinans L. (Acanthaceae) populations have expanded their ranges northward since the LGM $[18,19]$. For both species, there is evidence of long-distance dispersal (LDD) $[18,20]$, reinforcing the key role of dispersal as an important biogeographic mechanism in the process of population extinction and posterior recolonization [18]. To expand on these efforts and to better understand how mangrove forests have been changing in response to historical factors and processes, we studied the phylogeographic patterns of two Avicennia species of the Western Hemisphere: Avicennia germinans and A. schaueriana Moldenke. The former is a widespread species found throughout most of the ACEP region, whereas the latter is restricted to the Atlantic coast of South America and the southern Caribbean [1,21,22] (Figure 1).

The genetic structure of these species is influenced by intrinsic factors, such as mixed mating systems, biparental inbreeding, ongoing hybridization, and rate of gene flow through pollen and propagule dispersal [18,23-26], and by extrinsic factors, such as marine currents and tidal patterns [26]. The combination of this complex set of ecological features that shape the genetic diversity of $A$. germinans and A. schaueriana

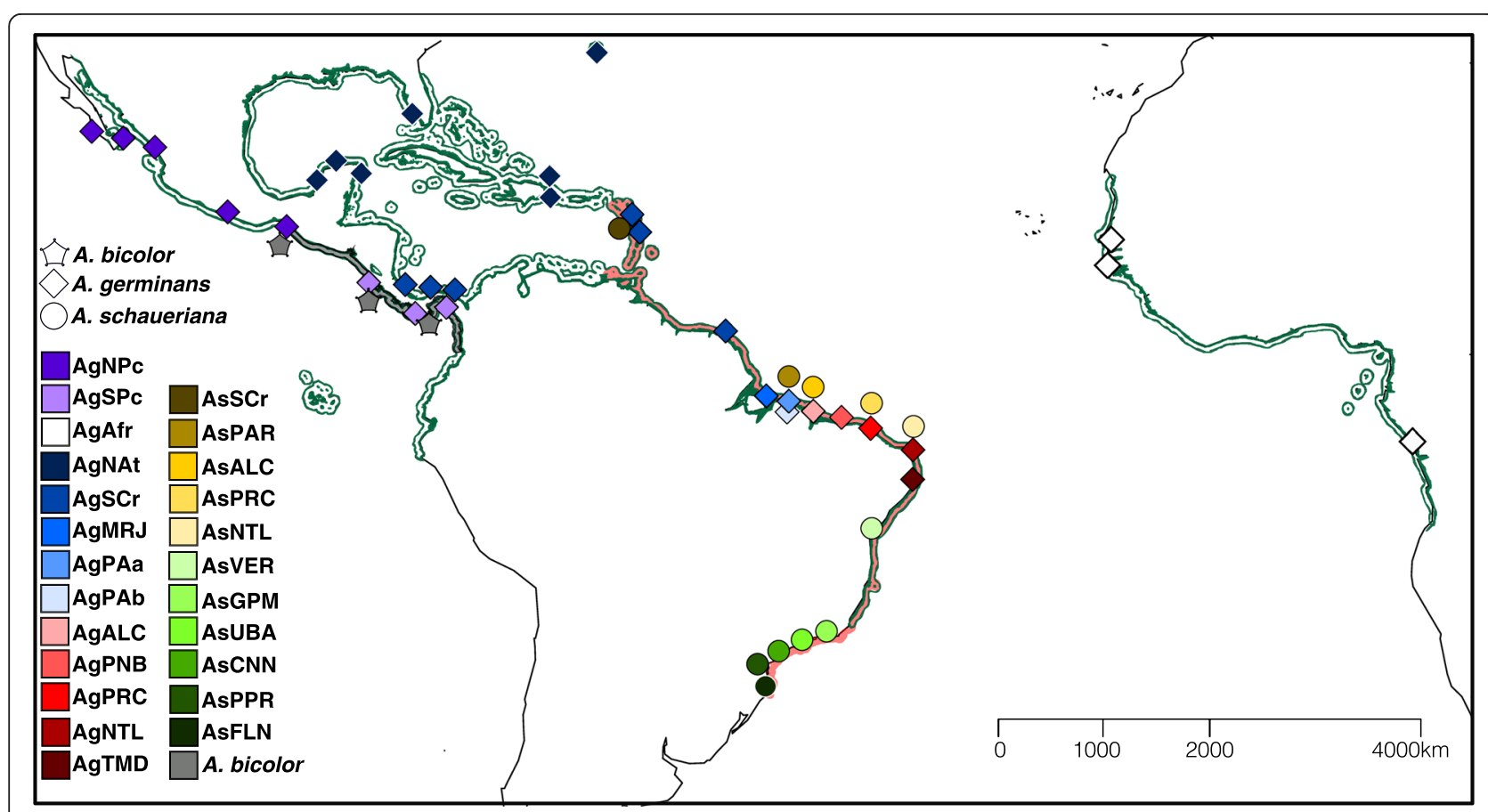

Figure 1 Map showing sampling design. Locations of the samples of Avicennia bicolor, A. germinans and A. schaueriana (represented by the shape of the polygons) across the Western Hemisphere. The color of each polygon refers to the geographic region where the sample was obtained according to Additional file 1. The current geographic distributions of A. bicolor, A. germinans and A. schaueriana are shown along the coastlines of the continents in gray, green and red, respectively; the zones of sympatry between the species are denoted by overlapping colors. 
and historical processes, such as global climate changes after the LGM, may shed light on possible explanations for the current distribution of mangrove species in South America $[1,21,22]$.

Our main objective was to evaluate the genetic variation in the Avicennia species extending across nearly the entire mangrove forest distribution in the Western Hemisphere and to unveil some evolutionary processes that could have shaped this genetic diversity. Through intensive and extensive sampling along the Brazilian coastline, coupled with samples from the Pacific coastline areas of Central America, the Caribbean and West Africa $[18,23]$ and the sequencing of chloroplast and nuclear DNA (cpDNA and nDNA, respectively) markers, we provide a large-scale assessment of the genetic variation of Avicennia covering nearly the entire ACEP region. This strategy enabled us to gain a broad molecular perspective on the evolutionary history of the genus, including the three species found in this biogeographic region: A. germinans, A. schaueriana and A. bicolor Standl.; the distribution of $A$. bicolor is restricted to the Pacific coast of Central America (Figure 1). This distribution of species is particularly interesting because there is evidence to suggest that there has been ancient hybridization between A. germinans and A. bicolor within their zone of sympatry [23] and an ongoing and unidirectional introgression process between A. germinans and A. schaueriana on the northern coast of South America [23,26]. We also studied the geographic distribution of the genetic diversity across the ACEP region to better comprehend the previously described complex interplay between the intrinsic and extrinsic factors that are influencing the neutral genetic variation of the species [26]. We then evaluated the evidence for the historical demographic fluctuations of $A$. germinans and A. schaueriana and the historical ecological differences between them to explain the current pattern of species distribution along the South American continent.

\section{Methods}

\section{Plant material}

We sampled 138 A. germinans and 193 A. schaueriana individuals from 11 locations along the Brazilian coastline; the samples were georeferenced using a global positioning system (Garmin 76CSx, considering the WGS84 standard) (Figure 1 and Additional file 1). For simplicity, each sample is henceforth denoted as in Additional file 1 , with $\mathrm{Ag}$ and As indicating $A$. germinans and $A$. schaueriana, respectively, followed by a three-letter abbreviation corresponding to the site where the individuals were obtained. These species were identified in the field based both on their floral structures and vegetative branches [1] to minimize the chances of misidentification. Voucher specimens from every site, except for Alcântara, Maranhão, were deposited in the EMBRAPA
Amazônia Oriental (IAN) and University of Campinas (UEC) herbaria.

From each individual plant, we selected young and visually healthy leaves and maintained them in sealed bags containing silica gel; the samples were kept in the bags until being lyophilized and then stored at $-20^{\circ} \mathrm{C}$. The desiccated material was then ground into a fine powder using liquid nitrogen, and the resulting powder was used to isolate total DNA via a cetyltrimethylammonium bromide protocol.

\section{Genetic analyses}

To evaluate the distribution of the genetic variation, we sequenced two intergenic spacers of the chloroplastidial genome and one region of the nuclear ribosomal internal transcribed spacer (ITS). The trnD-trnT and $\operatorname{trn} \mathrm{H}-\operatorname{trnK}$ spacers of the cpDNA were amplified using the previously described DT and HK primer sets [27], and the polymerase chain reaction (PCR) amplification of the ITS region was performed using the previously described LEU1 and ITS4 primers [28]. The sequencing reactions were performed using two primers specific to the $\operatorname{trn} \mathrm{D}-\operatorname{trn} \mathrm{T}$ and ITS markers, and the $\operatorname{trn} \mathrm{H}-\operatorname{trn} \mathrm{K}$ locus was partially sequenced with primer $\mathrm{H}$, as performed by Nettel and colleagues [23]. The sequences were deposited in the DNA Data bank of Japan (Additional file 1). To augment the geographic distribution of our study and to include samples of $A$. bicolor and of two Avicennia species from the IWP biogeographic region, A. alba Blume and A. marina (Forssk.) Vierh., we also included previously analyzed sequences [18,23]. For populationlevel analyses, we only considered samples with eight or more individuals and used the chloroplast and nuclear markers that were available from each geographic region. Due to the differences in the publicly available sequences of previous studies [18,23], we considered different numbers of individuals for the cpDNA and nDNA markers (see Additional file 1).

We assembled and manually verified the chromatograms using CLC Genomics Workbench 4.9 software (CLC Bio). When we detected evidence of heterozygotes, three new amplifications and sequencing reactions were conducted as follows: only consistent double peaks were considered to be an indicator of a heterozygous site. The alignment and phasing of the entire dataset were performed using MUSCLE [29] and PHASE [30], respectively, and the haplotypes were unambiguously reconstructed. Due to the assumed maternal inheritance of the cpDNA with a low recombination rate, the $\operatorname{trn} \mathrm{D}-\operatorname{trn} \mathrm{T}$ and $\operatorname{trn} \mathrm{H}$ $\operatorname{trnK}$ spacers were concatenated and will henceforth be jointly referred to as DTHK. To understand the genealogical relationships among the ACEP region samples, we applied the median joining method [31] implemented in PopART (http://popart.otago.ac.nz/index.shtml [32]), using 
default settings to consider multifurcations and/or reticulations in a phylogenetic network approach.

We next determined the haplotype frequencies of each sample and calculated the haplotype diversity (h), nucleotide diversity $(\pi)$, and estimates of group pairwise $\Phi_{\mathrm{ST}}$ values, considering the haplotype frequency using Arlequin 3.5 [33]. For further population-level analyses, we only considered groups with eight or more individuals per group (Table 1 ). The pairwise $\Phi_{\mathrm{ST}}$ matrix was then dimensionally represented using multidimensional scaling (MDS) in R software [34]. The global values of $\mathrm{G}_{\mathrm{ST}}$, Nei's coefficient of multiple alleles gene differentiation analog to Wright's $\mathrm{F}_{\mathrm{ST}}[35,36]$, were inferred using DnaSp5.1 [37], considering gaps as the fifth state and haplotype data information [36]. Then, to compare the migration via pollen and seed, we estimated the pollento-seed migration ratio as $\left(r=m_{p} / m_{s}=\left\{\left(1 / G_{\text {STbipar }}-1\right)\right.\right.$
$\left.\left.\left(1+\mathrm{F}_{\mathrm{IS}}\right)-2 \quad\left(1 / \mathrm{G}_{\mathrm{STmat}}-1\right)\right\} /\left(1 / \mathrm{G}_{\mathrm{STmat}}-1\right)\right) \quad$ [38], given the global $G_{\text {ST }}$ of each marker $\left(G_{\text {STbipar }}\right.$ for ITS and $\mathrm{G}_{\mathrm{STmat}}$ for DTHK) and the previous average values of $\mathrm{F}_{\mathrm{IS}}$ estimated for A. germinans (0.174) and A. schaueriana (0.242) using microsatellites [26]. By doing so, we assumed that the extent of inbreeding, $\mathrm{F}_{\mathrm{IS}}$, is constant through time and also across the species populations.

To better understand the phylogeographic patterns of the observed genetic variation, and because the previously analyzed sequences were obtained from a few samples from each location [18,23], we arbitrarily grouped them into "geographic regions" according to previous studies [18,23,26] (see Additional file 1). Employing Arlequin 3.5 software [33], we studied the geographic distribution of the genetic diversity using a hierarchical analysis of molecular variance (AMOVA) [39] that considered different hypotheses for cpDNA and nDNA for

Table 1 Descriptive statistics for the Avicennia samples

\begin{tabular}{|c|c|c|c|c|c|c|c|c|c|c|c|c|c|}
\hline \multirow[b]{2}{*}{ Geographic region } & \multirow[b]{2}{*}{ Statistics } & \multicolumn{6}{|l|}{ ITS } & \multicolumn{6}{|c|}{ DTHK } \\
\hline & & $\mathbf{n}$ & $N_{\text {subst }}$ & $\pi$ & $h$ & (SD) & $\mathrm{N}_{\text {hap }}$ & $n$ & $N_{\text {subst }}$ & $\pi$ & $h$ & (SD) & $\mathrm{N}_{\text {hap }}$ \\
\hline IWP & A. alba & 1 & 0 & 0 & 0 & $(0)$ & 1 & 1 & 0 & 0 & 0 & (0) & 1 \\
\hline ACEP & A. bicolor & 6 & 0 & 0 & 0 & $(0)$ & 1 & 6 & 0 & 7.091 & 0 & $(0)$ & 1 \\
\hline IWP & A. marina & 2 & 1 & 0.667 & 0.667 & $(0.204)$ & 2 & 2 & 1 & 399.333 & 0.667 & $(0.204)$ & 2 \\
\hline North Pacific & $\mathrm{AgNPC}$ & 10 & 5 & 0.947 & 0.795 & $(0.065)$ & 6 & 8 & 0 & 0 & 0.433 & $(0.138)$ & 3 \\
\hline South Pacific & $\mathrm{AgSPC}$ & 20 & 10 & 3.358 & 0.922 & $(0.022)$ & 16 & 18 & 1 & 0.203 & 0.298 & (0.093) & 3 \\
\hline West Africa & AgAfr & 4 & 1 & 0.429 & 0.429 & $(0.169)$ & 2 & 1 & 0 & 0 & 0 & (0) & 1 \\
\hline North Atlantic & AgNAt & 6 & 0 & 0 & 0 & (0) & 1 & 2 & 0 & 0 & 0 & (0) & 1 \\
\hline South Caribbean & $\mathrm{AgSCr}$ & 7 & 1 & 2.901 & 0.264 & $(0.136)$ & 2 & 1 & 0 & 0 & 0 & $(0)$ & 1 \\
\hline Marajó, Brazil & AgMRJ & 24 & 2 & 0.083 & 0.728 & $(0.041)$ & 8 & 24 & 1 & 0.223 & 0.223 & $(0.072)$ & 2 \\
\hline Pará*, Brazil & AgPAa & 25 & 1 & 0.115 & 0.418 & $(0.086)$ & 7 & 25 & 4 & 0.601 & 0.353 & $(0.083)$ & 4 \\
\hline Pará, Brazil & AgPAb & 16 & 5 & 0.71 & 0.698 & $(0.08)$ & 7 & 16 & 9 & 1.427 & 0.389 & $(0.106)$ & 5 \\
\hline Alcântara, Brazil & $\mathrm{AgALC}$ & 21 & 1 & 0.418 & 0.519 & $(0.091)$ & 8 & 21 & 8 & 2.499 & 0.4 & $(0.085)$ & 3 \\
\hline Parnaíba, Brazil & AgPNB & 24 & 1 & 0.284 & 0.301 & $(0.083)$ & 4 & 24 & 0 & 0 & 0 & (0) & 1 \\
\hline Paracuru, Brazil & AgPRC & 4 & 4 & 1.821 & 0.607 & $(0.164)$ & 3 & 8 & 4 & 3.857 & 0.429 & $(0.169)$ & 2 \\
\hline Natal, Brazil & AgNTL & 2 & 0 & 0 & 0 & $(0)$ & 1 & & & & & & \\
\hline Tamandaré, Brazil & AgTMD & 24 & 3 & 0.319 & 0.301 & $(0.083)$ & 4 & 24 & 1 & 0.383 & 0.401 & $(0.072)$ & 3 \\
\hline South Caribbean & AsSCr & 1 & 0 & 0 & 0 & (0) & 1 & 1 & 0 & 0 & 1 & $(0.5)$ & 2 \\
\hline Pará, Brazil & AsPAR & 26 & 4 & 0.51 & 0.59 & $(0.069)$ & 6 & 26 & 11 & 1.988 & 0.793 & $(0.05)$ & 12 \\
\hline Alcântara, Brazil & AsALC & 22 & 0 & 0 & 0.453 & $(0.085)$ & 5 & 22 & 0 & 0 & 0 & (0) & 1 \\
\hline Paracuru, Brazil & AsPRC & 16 & 0 & 0 & 0.669 & $(0.035)$ & 3 & 16 & 0 & 0 & 0 & (0) & 1 \\
\hline Natal, Brazil & AsNTL & 1 & 0 & 0 & 0 & $(0)$ & 1 & 1 & 0 & 0 & 0 & $(0)$ & 1 \\
\hline Vera Cruz, Brazil & AsVER & 16 & 8 & 1.196 & 0.341 & $(0.105)$ & 5 & 16 & 2 & 0.242 & 0.234 & $(0.095)$ & 3 \\
\hline Guapimirim, Brazil & AsGPM & 24 & 5 & 2.097 & 0.781 & $(0.045)$ & 12 & 24 & 1 & 0.082 & 0.082 & $(0.053)$ & 2 \\
\hline Ubatuba, Brazil & AsUBA & 21 & 0 & 0 & 0.251 & $(0.078)$ & 2 & 21 & 0 & 0 & 0 & $(0)$ & 1 \\
\hline Cananéia, Brazil & AsCNN & 23 & 0 & 0 & 0.125 & $(0.063)$ & 2 & 23 & 0 & 0 & 0 & (0) & 1 \\
\hline Pontal do Paraná, Brazil & AsPPR & 23 & 4 & 1.337 & 0.477 & $(0.087)$ & 7 & 23 & 1 & 0.085 & 0.085 & $(0.055)$ & 2 \\
\hline Florianópolis, Brazil & AsFLN & 22 & 0 & 0 & 0 & (0) & 1 & 22 & 2 & 0.178 & 0.254 & $(0.085)$ & 4 \\
\hline
\end{tabular}

The species names and sample abbreviations are identical to those used in Figure 1 and Additional file 1. $n$, sample size; $N_{\text {subst, }}$ number of substitutions; $\pi$, nucleotide diversity; $h$ (SD), haplotype diversity and (standard deviation of haplotype diversity); $N_{h a p}$, number of haplotypes. 
each species. We created different a priori hypotheses regarding $A$. germinans and A. schaueriana based on several factors: a) the geographic influences of the American continent, b) the effects of contemporary near-surface marine currents on the genetic diversity of ACEP mangrove species $[17,18,20,25,26,40]$, and c) the forest continuum of the Amazon Macrotidal Mangrove Coast (AMMC) [41], which includes samples from Pará and Maranhão States, (Figure 1 and Additional file 1). We also tested $a$ posteriori groups regarding the genealogical analysis and the geographic distribution of haplotypes. The criteria for determining the best hypothesized arrangement were a significant departure from a random distribution and the maximum variance among groups $\left(\Phi_{\mathrm{CT}}\right)$. We used PERMUT software [42] to test whether different haplotypes that occurred within populations were more closely related than distinct haplotypes from different population by estimating and comparing the $\mathrm{N}_{\mathrm{ST}}$, which considers both haplotype frequencies and their divergence, and $\mathrm{G}_{\mathrm{ST}}$, which only considers haplotype frequencies, based on 10,000 random permutations.

We evaluated the demographic fluctuations using several summary statistics and considered the groups that best met the maximum significant $\Phi_{\mathrm{CT}}$ criterion and the sample arrangements previously inferred using other genetic markers, such as microsatellites $[17,18,23,26]$. This approach of evaluating two distinct scenarios is justified by the differences between the sets of markers that were previously used to study the genetic diversity and the markers used in this study. We evaluated different neutrality tests: Tajima's D [43] and Fu's $F_{S}$ [44] using Arlequin 3.5 [33] and $\mathrm{D}^{*}$ and $\mathrm{F}^{*}$ [45] computed with DnaSP 5.1 [37]. Assuming the loci to be selectively neutral, we justified the use of these statistics by their different statistical power and sensitivity to recombination [46]. We then considered Fu's $F_{S}$ [44] for the DTHK marker and Tajima's D [43], $\mathrm{D}^{*}$ and $\mathrm{F}^{*}$ [45] for the ITS marker because, as expected, the latter presented more evidence of recombination than the former (data not shown). We then used Arlequin 3.5 to calculate the mismatch distribution of the observed number of differences between haplotype pairs to evaluate demographic expansions by analyzing the raggedness index [47]. These analyses of the distributions of pairwise differences were considered to be complementary evidence of demographic expansions when neutrality tests significantly departed from random distributions due to their conservativeness [48]. Regarding the ITS region, when only $\mathrm{D}^{*}$ and $\mathrm{F}^{*}$ [45] are significant, background selection is indicated as the likely mechanism underlying the polymorphism, and the opposite suggests population growth [44]. Significant negative values of Tajima's D and Fu's Fs are evidence of population growth, whereas a significant positive Tajima's D is associated with population decline.
Population expansion would also lead to a smooth mismatch distribution, and small raggedness values indicate a smooth mismatch distribution.

\section{Ethics statement}

We obtained two licenses (Nos. 17159 and 17130) to collect the leaves and propagules of $A$. germinans and A. schaueriana from the Brazilian Institute of the Environment and Natural Renewable Resources - IBAMA (currently Chico Mendes Institute for Biodiversity Conservation - ICMBio). We confirm that A. germinans and $A$. schaueriana are not endangered or protected species.

\section{Results}

To evaluate the distribution of the genetic diversity of the three Avicennia species on the scale of the entire Western Hemisphere, we obtained samples of $A$. germinans and A. schaueriana from northeastern and southern South America and studied them together with previously evaluated samples using cpDNA and nDNA markers [18,23]. The total number of individuals per sample and the descriptive statistics regarding the genetic diversity are shown in Table 1 . The numbers of polymorphic sites we observed were 91 and 129, totaling 28 and 72 haplotypes for the DTHK and ITS loci, respectively; the haplotype $(h)$ and nucleotide $(\pi)$ diversities (Table 1) varied substantially among populations. As expected, each species had unique haplotypes for each marker, but we observed shared haplotypes between individuals identified as $A$. germinans and $A$. schaueriana along the northeastern coast of South America (Figure 2). One of these shared ITS and DTHK haplotypes was also observed in the African A. germinans samples (Figure 2).

\section{Genealogical relationships}

The median-joining haplotype network of each marker indicated a deep divergence between the IWP and ACEP species and an intricate relationship among the samples of the latter (Figure 2). At the species level, as expected, the haplotypes were mostly congruent with each taxon, indicating complete lineage sorting for both the ITS and the DTHK. However, the geographic distribution of the haplotypes was slightly different when each of these markers was considered. Regarding the nDNA sequences (Figure 2A), there was a strong relationship between the geographic origin and haplotype for some samples, such as the Pacific, southern Caribbean and North Atlantic samples of $A$. germinans. However, when mainly A. germinans and A. schaueriana samples from the Brazilian coast were considered, there was no obvious pattern of genetic structure due to haplotype sharing among samples from different geographic origins. A 


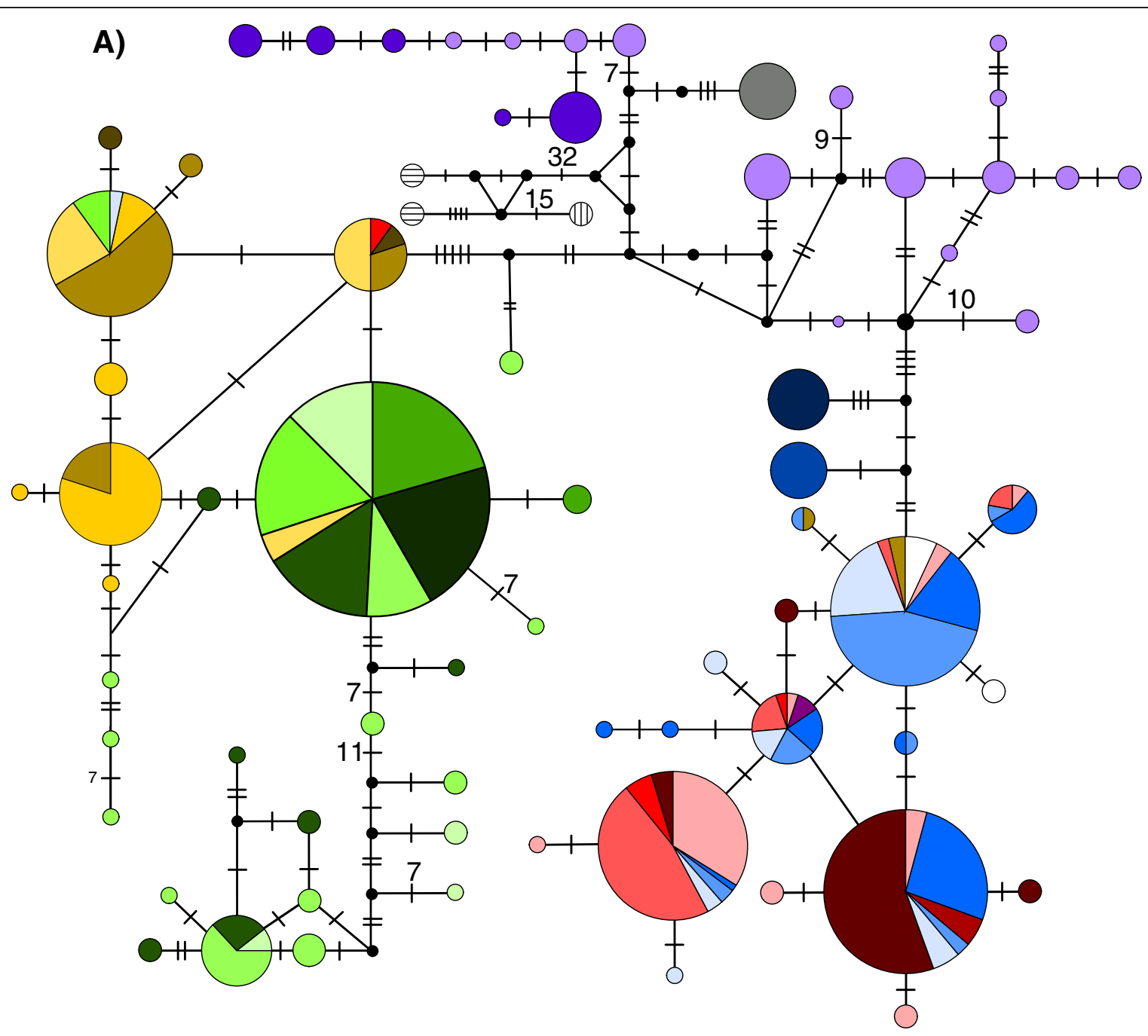

B)

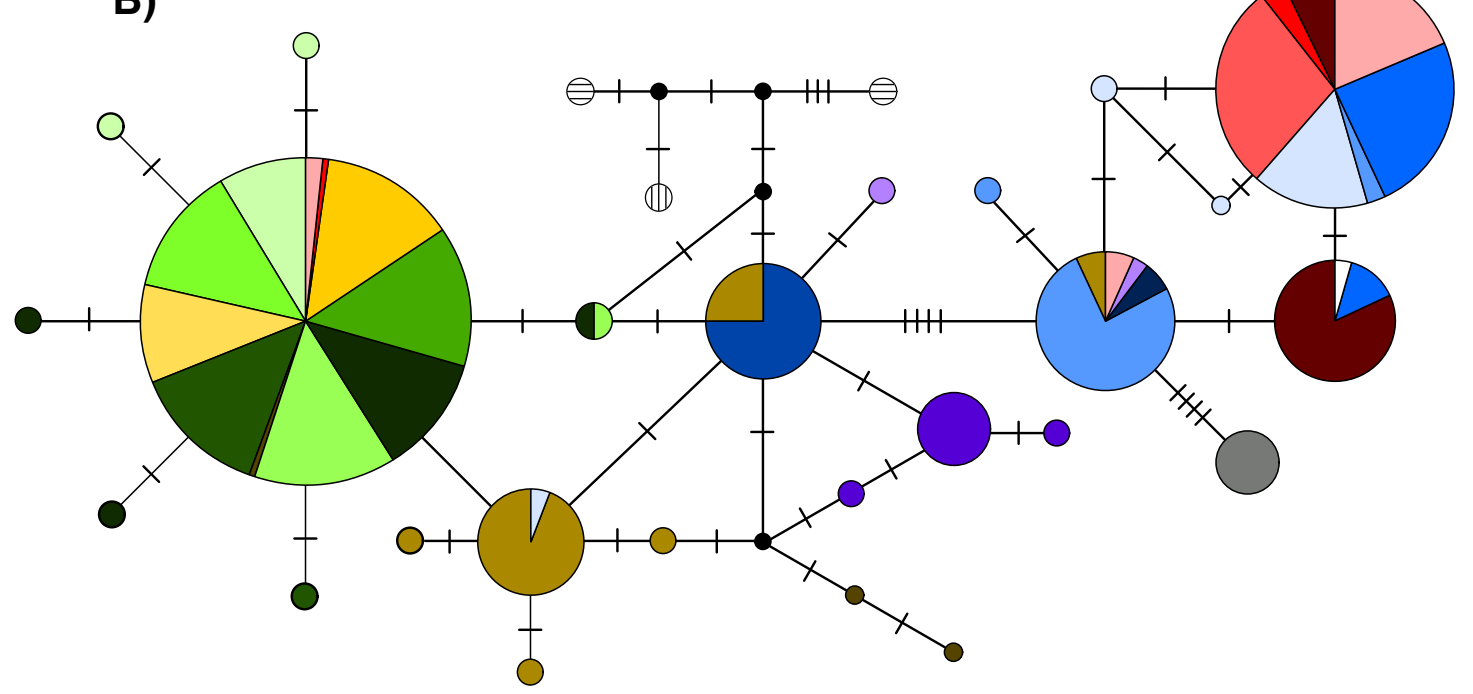

Figure 2 (See legend on next page.) 
(See figure on previous page.)

Figure 2 Median joining networks of cpDNA and nDNA of Avicennia species. The haplotype networks of the A) ITS and B) DTHK markers in Avicennia species from the Western, A. bicolor, A. germinans and A. schaueriana, and Eastern Hemispheres, A. marina and A. alba. Each line in the network refers to a single-nucleotide mutation, the double bars combined with numbers indicate the numbers of mutations between haplotypes, and the black dots indicate missing haplotypes in the samples. The circles denote unique haplotypes and are proportional to the number of sequences, with colors representing the samples according to Figure 1 and Additional file 1. A. marina and A. alba, species from the Eastern Hemisphere, are denoted as circles with vertical and horizontal lines, respectively

highly divergent group composed of the AsPPR, AsGPM and AsVER samples was also observed, supporting the ITS phylogenetic tree (Figure 2A). Given the cpDNA sequences (Figure 2B), the geographic structure of the genetic diversity was similar to that observed for the nDNA marker: A. germinans samples from West Africa, the North Atlantic and the southern Caribbean composed a distinct group, and the Pacific haplotypes composed another clear cluster. As was observed for the ITS marker (Figure 2A), the Brazilian samples of $A$. germinans presented a more complex phylogeographic pattern. In the A. schaueriana samples, there was a dominant haplotype that was shared by most of the individuals, whereas the AsPAR samples presented a group of closely related haplotypes.

Regardless of the marker considered, we found evidence of 'star-like' genealogies [49], where sampled lineages experienced independent evolution since their most recent common ancestor, which may be considered as preliminary signals of recent demographic expansions $[50,51]$. Moreover, the haplotype network constructed for both markers demonstrated that some individuals identified as $A$. germinans presented haplotypes that are in much higher frequency in A. schaueriana individuals and that this observation was reciprocal.
Population-level analyses of $A$. germinans and $A$. schaueriana Population differentiation analyses indicated that there was intraspecific genetic divergence between the evaluated samples of A. germinans and A. schaueriana (global $\mathrm{G}_{\mathrm{ST}}$ values [36] of 0.568 and 0.340 for the former, and 0.397 and 0.386 for the latter, for the DTHK and ITS markers, respectively). The differences between inferences of $\mathrm{G}_{\mathrm{ST}}$ by means of these markers indicated that A. germinans had a pollen-to-seed ratio of $\mathrm{r}=0.996$, whereas the pollen-to-seed ratio of $A$. schaueriana was negative or practically zero $(\mathrm{r}=-0.699)$. This difference suggests that the gene flow of $A$. germinans through its propagules was similar to the gene flow by pollen; however, in A. schaueriana, the movement of genes by seeds was one to two times higher than that by pollen.

The $\mathrm{G}_{\mathrm{ST}}$ values indicated that there was substantial genetic structure, which is more readily observed when one considers the pairwise $\Phi_{\mathrm{ST}}$ values for each species, which were mostly significant, except for the cpDNA marker and the A. schaueriana samples (see Additional file 2). The overall organization of the genetic diversity was complex, as shown by the graphical representation of the MDS analyses (Figure 3), which resulted in relatively reliable models; the lowest measure of the goodness of fit when considering the two dimensions was 0.7893 .

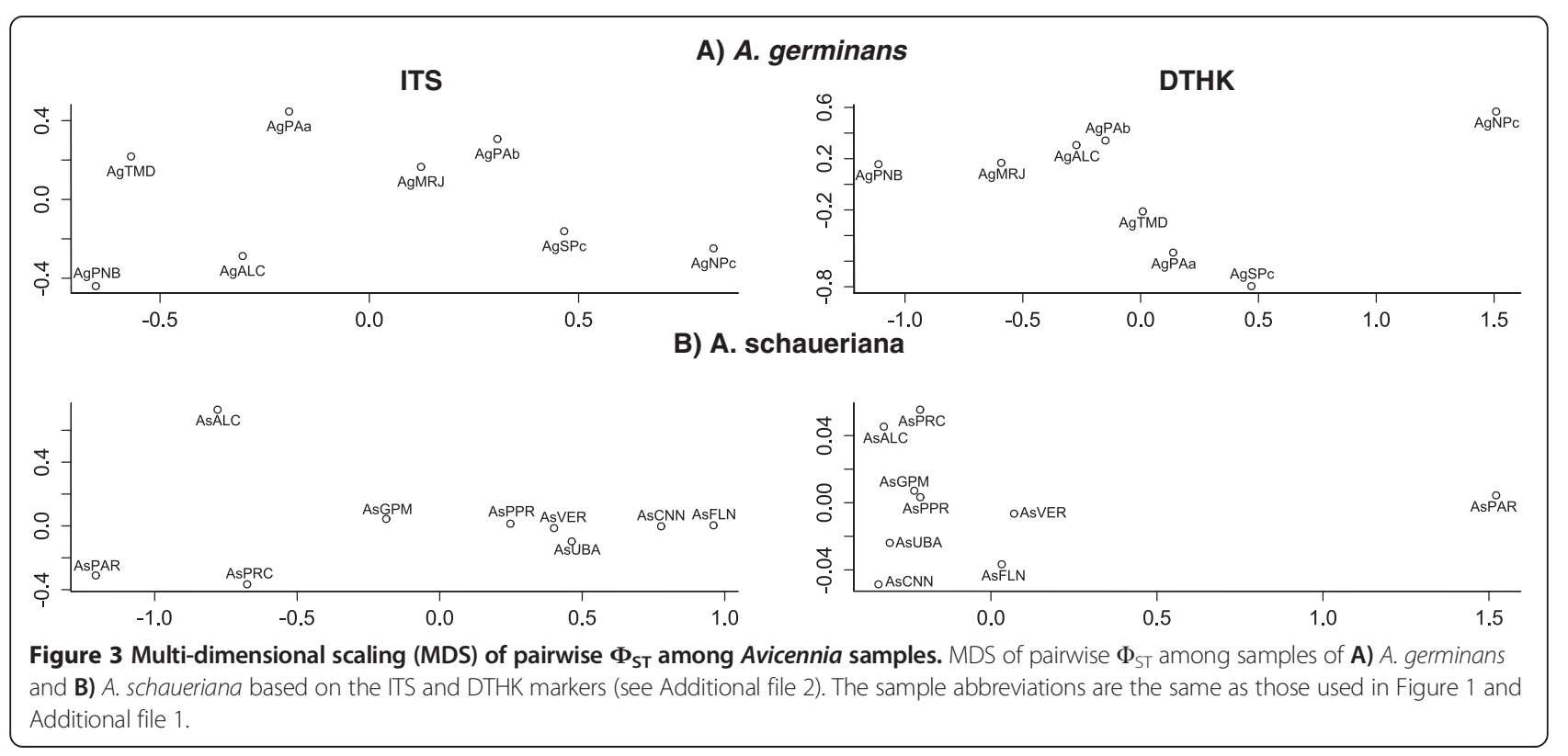


To better understand this intricate pattern of genetic structure, we explicitly tested for different geographic grouping hypotheses (Table 2). Despite previous studies that found evidence of genetic structure in three mangrove species (A. germinans, A. schaueriana and $R$. mangle) from the ACEP region $[17,20,26]$, the AMOVA results considering the cpDNA and nDNA markers of both A. germinans and $A$. schaueriana indicated that a posteriori hypotheses provided better explanations for the observed molecular variation. The a priori models considered different combinations of the expected effects of the AMMC, the American continent and/or prominent surface marine currents on the genetic diversity. The hypothesized groupings of Ag1, Ag4, As1, As8 and As9 were based on previous studies that used molecular markers to evaluate the genetic variation $[17,18,20,23,52]$. In general, these hypotheses performed worse than our a posteriori models because the $\Phi_{\mathrm{CT}}$ values were not significantly different from random distributions, and due to the highly negative values of among-group variance, they failed to reasonably explain the genetic diversity (Table 2). For A. germinans, no hypothesis was consistently supported by the AMOVA outcomes; coupled with the high and significant pairwise $\Phi_{\mathrm{ST}}$ values. This finding indicates that the genetic variation is likely to be organized among samples with relatively limited gene flow among them. Conversely, for $A$. schaueriana, model As6 was consistently supported by both the DTHK and ITS markers despite the extremely low variation among groups $\left(\Phi_{\mathrm{ST}}=0.46969\right)$ when the former was analyzed (Table 2).

Considering both the genetic structure identified herein (in model As6 and when considering each sample separately for A. germinans) and the a priori scenarios, namely models Ag1 and As1, based on previous studies $[17,18,20,25,26,40]$, we observed different indications of recent demographic expansions in both species from both the a priori and a posteriori hypotheses. When $A$. germinans model Ag1 was considered, we found signs of expansion in the AgNPc and AgNAtl groupings, whereas AgSPc showed indications of background selection. When each population was considered, only AgALC, AgPNB and AgTMD did not present signs of demographic changes (Table 3 ). These results are only supported by the ITS marker, whereas both the nDNA and cpDNA loci suggest that recent population growth has also occurred in A. schaueriana. Regarding both the hypothesized models, there were signs of expansion in every group except for AsFLN (Table 3).

Regarding the PERMUT analysis, we observed that for A. germinans, the provided ITS and DTHK markers pointed to a significant $(\mathrm{P}<0.05)$ difference between the mean values of $\mathrm{G}_{\mathrm{ST}}(0.274$ and 0.528 , respectively) and $\mathrm{N}_{\mathrm{ST}}$ (0.559 and 0.733, respectively). In contrast, for $A$. schaueriana, the differences between these indexes were not significant $(\mathrm{P}>0.05)$ : for ITS and DTHK markers, the mean values of $\mathrm{G}_{\mathrm{ST}}$ were 0.384 and 0.442 , respectively, whereas the mean values for $\mathrm{N}_{\mathrm{ST}}$ were 0.302 and 0.400 , respectively.

\section{Discussion}

The presence of interspecific hybridization in Avicennia species at the Western Hemisphere

By means of both haplotype networks, we observed that the three Avicennia species from the ACEP region may be considered three different evolutionary lineages independent from the lineage composed of $A$. alba and $A$. marina, which are IWP species (Figure 2). However, the isolation of these species is not absolute. Although there is no evidence of ongoing hybridization between $A$. bicolor and $A$. germinans, an ancient introgression between them has already been reported [23], and evidence for this historical contact between these species (the incongruent phylogenetic relationship between the cpDNA and the nDNA) was also observed in this work with the inclusion of more samples of $A$. germinans and $A$. schaueriana from the southeastern coast of South America (Figure 2).

On the other side of the American continent, even more interestingly, we found new evidence of current hybridization between A. germinans and A. schaueriana. Using microsatellites, we have previously observed that these two species may interbreed, and, furthermore, that this hybridization is asymmetric because only individuals identified as A. germinans presented signals of interspecific breeding (evidence of F1 individuals and trees originated from backcrosses between F1 hybrids and $A$. germinans within the zone of sympatry for this species and A. schaueriana.) [26]. Herein, we find additional evidence of this hybridization, but the new data do not support this asymmetry. Using DTHK and ITS haplotype sharing, we found additional evidence of interbreeding between $A$. schaueriana and A. germinans from several locations within the zone of sympatry for these species, indicating that this biological process may be more common than previously believed. We favor hybridization/introgression rather than an ancestral polymorphism as the most likely mechanism generating this haplotype sharing due to the positions in the phylogenetic networks and the relatively high frequencies of the shared haplotypes. The branches where these haplotypes occurred, however, are not more related to the IWP species, as would be expected for this biological process (Figure 2), and two of the four haplotypes shared by these species were rare (less than $3 \%$ ), whereas ancestral haplotypes are presumed to be more frequent. Moreover, because there are individuals that were identified as either A. germinans and A. schaueriana, while sharing reciprocal haplotypes, $\mathrm{cpDNA}$ and $\mathrm{nDNA}$ data no longer 
Table 2 Analysis of molecular variance for five different grouping models for A. germinans and A. schaueriana

\begin{tabular}{|c|c|c|c|c|c|c|c|c|c|c|c|c|}
\hline \multicolumn{13}{|c|}{ A. germinans } \\
\hline & & \multirow{3}{*}{$\begin{array}{l}\text { Hypothesized grouping } \\
{[\text { Atlantic][Pacific] }}\end{array}$} & \multicolumn{5}{|l|}{ DTHK } & \multicolumn{5}{|l|}{ ITS } \\
\hline \multicolumn{2}{|c|}{ Hypothesis } & & $\Phi_{\mathrm{sc}}$ & $\Phi_{\text {ST }}$ & $\Phi_{\mathrm{GT}}$ & $\%$ Among groups & $\mathrm{P} \boldsymbol{\Phi}_{\mathrm{GT}}$ & $\Phi_{\mathrm{sc}}$ & $\Phi_{\text {ST }}$ & $\Phi_{\mathrm{GT}}$ & $\%$ Among groups & $P \Phi_{G T}$ \\
\hline $\mathrm{Ag} 1$ & a priori & & 0.631 & 0.222 & -1.112 & -111.210 & $0.17822 \pm 0.00343$ & 0.438 & -0.115 & -0.983 & -98.340 & $0.10891 \pm 0.00318$ \\
\hline $\mathrm{Ag} 2$ & a priori & [Atlantic][AgNPc][AgAgSPc] & 0.668 & 0.385 & -0.854 & -85.440 & $0.85297 \pm 0.00321$ & 0.668 & 0.385 & -0.854 & -85.440 & $0.85297 \pm 0.00321$ \\
\hline Ag3 & a priori & [North Brazil][South Brazil][Pacific] & 0.722 & 0.313 & -1.470 & -147.010 & $0.83010 \pm 0.00390$ & 0.534 & -0.331 & -1.853 & -185.350 & $0.52743 \pm 0.00479$ \\
\hline Ag4 & a priori & {$[\mathrm{AgNAt}][\mathrm{AgSAt}][\mathrm{AgSPc}][\mathrm{AgNPc}]$} & 0.837 & 0.802 & -0.218 & -21.780 & $0.35881 \pm 0.00483$ & 0.786 & 0.775 & -0.052 & -5.240 & $0.27693 \pm 0.00469$ \\
\hline Ag5 & a priori & [AgSPc][AgNPc][AMMC][AgPNB][AgTMD] & -1.697 & 1.162 & 1.060 & 106.020 & $0.25505 \pm 0.00461$ & 2.015 & 1.082 & 0.919 & 91.920 & $0.15188 \pm 0.00399$ \\
\hline \multirow[t]{2}{*}{ Ag6 } & a posteriori & [AgSPc][AgNPc][AgPAa][AgTMD] & -0.107 & 1.117 & 1.106 & 110.560 & $0.05733 \pm 0.00228$ & -2.430 & 1.149 & 1.043 & 104.340 & $0.32436 \pm 0.00428$ \\
\hline & & {$[\mathrm{AgPAb}+\mathrm{AgTMD}+\mathrm{AgPNB}]$} & & & & & & & & & & \\
\hline \multirow[t]{2}{*}{ Ag7 } & a posteriori & [AgSPc][AgNPc][AMMC][AgPAa] & -0.019 & 0.978 & 0.978 & 97.820 & $0.30198 \pm 0.00477$ & -0.211 & 0.949 & 0.958 & 95.810 & $0.38851 \pm 0.00487$ \\
\hline & & [AgTMD][AgPNB] & & & & & & & & & & \\
\hline Ag8 & a posteriori & $\begin{array}{l}\text { [AgSPc][AgNPc][AgPAa + AgTMD] } \\
{[\mathrm{AgPab}+\mathrm{AgMRJ}+\mathrm{AgALC}][\mathrm{AgPNB}]}\end{array}$ & 0.262 & 0.830 & 0.770 & 77.010 & $0.03465 \pm 0.00186$ & 7.792 & 1.028 & 0.996 & 99.590 & $0.77861 \pm 0.00409$ \\
\hline \multicolumn{13}{|c|}{ A. schaueriana } \\
\hline & & & DTHK & & & & & ITS & & & & \\
\hline \multicolumn{2}{|c|}{ Hypothesis } & Hypothesized grouping & $\overline{\Phi_{\mathrm{SC}}}$ & $\boldsymbol{\Phi}_{\mathrm{ST}}$ & $\Phi_{\mathrm{GT}}$ & $\%$ Among groups & $\mathbf{P} \Phi_{\mathrm{GT}}$ & $\overline{\Phi_{\mathrm{sc}}}$ & $\Phi_{\text {ST }}$ & $\Phi_{\mathrm{GT}}$ & $\%$ Among groups & $P \Phi_{G T}$ \\
\hline As1 & a priori & [North Brazil][South Brazil] & 0.491 & -1.432 & -3.775 & -377.530 & $0.70446 \pm 0.00405$ & 0.255 & 4.543 & 5.756 & 575.630 & $0.99000 \pm 0.00098$ \\
\hline As2 & a priori & [AMMC][AsPRC][South Brazil] & 0.532 & -1.321 & -3.958 & -395.810 & $0.67614 \pm 0.00471$ & 0.291 & 3.318 & 4.270 & 426.970 & $0.96515 \pm 0.00183$ \\
\hline As3 & a posteriori & [AsPAR][AsALC + AsPRC][South Brazil] & -0.044 & 1.685 & 1.656 & 165.650 & $0.90881 \pm 0.00277$ & 0.333 & 3.617 & 4.922 & 492.150 & $0.97257 \pm 0.00164$ \\
\hline As4 & a posteriori & $\begin{array}{l}{[\text { AsPAR][AsALC + AsPRC+ AsGPM+ }} \\
\text { AsPPR + AsVER + AsUBA + AsFLN + AsCNN] }\end{array}$ & -0.030 & 5.706 & 5.569 & 556.910 & 1.000 & 0.442 & -0.056 & -0.893 & -89.280 & $1.00000+-0.00000$ \\
\hline \multirow[t]{2}{*}{ As5 } & a posteriori & [AsPAR][AsALC + AsPRC][AsGPM + AsPPR] & -0.145 & 1.080 & 1.070 & 106.990 & $0.96525 \pm 0.00180$ & 0.583 & 1.193 & 1.462 & 146.150 & $0.99436 \pm 0.00081$ \\
\hline & & {$[\mathrm{AsVER}+\mathrm{As} U \mathrm{BA}+\mathrm{AsFLN}+\mathrm{AsCNN}]$} & & & & & & & & & & \\
\hline \multirow[t]{2}{*}{ As6 } & a posteriori & [AsPAR]\{ AsALC + AsPRC][AsVER] & -0.021 & 0.458 & 0.470 & 46.970 & $0.01406 \pm 0.00122$ & 3.619 & 1.065 & 0.975 & 97.510 & $0.01436 \pm 0.00109$ \\
\hline & & {$[\mathrm{AsGPM}+\mathrm{AsPPR}+\mathrm{As} \cup \mathrm{BA}+\mathrm{AsCNN][AsFLN]}$} & & & & & & & & & & \\
\hline \multirow[t]{2}{*}{ As7 } & a posteriori & [AsPAR][AsALC + AsPRC][AsVER][AsGPM] & 0.018 & 0.869 & 0.867 & 86.650 & $0.85396 \pm 0.00306$ & -0.168 & 0.858 & 0.878 & 87.810 & $0.81059 \pm 0.00375$ \\
\hline & & {$[\mathrm{AsUBA}+\mathrm{AsCNN][AsPPR][AsFLN]}$} & & & & & & & & & & \\
\hline \multirow[t]{2}{*}{ As8 } & a priori & [AsPAR][AsALC][AsPRC][AsGPM] & -0.016 & 0.418 & 0.427 & 42.720 & $0.53287 \pm 0.00505$ & 0.001 & 0.882 & 0.882 & 88.220 & $0.89436 \pm 0.00248$ \\
\hline & & {$[\mathrm{AsPPR}+\mathrm{AsVER}+\mathrm{AsUBA}][\mathrm{AsCNN}+\mathrm{AsFLN}]$} & & & & & & & & & & \\
\hline \multirow[t]{2}{*}{ As9 } & a priori & [AsPAR][AsALC][AsPRC][AsGPM][AsVER] & 0.001 & 0.919 & 0.919 & 91.870 & $0.33327 \pm 0.00491$ & -0.012 & 0.911 & 0.912 & 91.150 & $0.35238 \pm 0.00448$ \\
\hline & & {$[\mathrm{As} U B A][\mathrm{AsPPR}+\mathrm{AsCNN}+\mathrm{AsFLN}]$} & & & & & & & & & & \\
\hline
\end{tabular}

Analysis of molecular variance for different grouping models based on previous hypotheses regarding the genetic structure based on microsatellite markers on the current distribution of mangrove forest (a priori hypotheses) and on the genealogical relationships of the haplotypes (a posteriori models). The acronyms refer to the geographic regions where samples were obtained and are identical to the remaining samples from the Brazilian coastline regions. AMMC designates samples from the Amazon Macrotidal Mangrove Coast from Pará and Maranhão States. 
Table 3 Neutrality tests for $A$. germinans and A. schaueriana

\begin{tabular}{|c|c|c|c|c|c|c|c|c|c|c|c|c|}
\hline \multicolumn{13}{|l|}{ A) A. germinans } \\
\hline \multirow{2}{*}{$\begin{array}{l}\text { ITS } \\
\text { Statistics }\end{array}$} & \multicolumn{4}{|c|}{ model Ag1 } & \multicolumn{8}{|c|}{ A. germinans populations } \\
\hline & AgNPc & AgSPc & $\mathrm{AgNBr}$ & AgTMD & AgNPc & AgSPc & AgMRJ & AgPAa & AgPAb & AgALC & AgPNB & AgTMD \\
\hline Tajima's D & -3.350 & -1.606 & -2.412 & -1.478 & -3.350 & -1.606 & -2.408 & -2.173 & -2.988 & -1.848 & -1.210 & -1.478 \\
\hline$D^{*}$ & 1.406 & 1.506 & 0.659 & 1.008 & 1.406 & 1.506 & 1.654 & -0.829 & 1.368 & 1.188 & 0.895 & 1.008 \\
\hline$F^{*}$ & 1.035 & 1.762 & -0.390 & 0.491 & 1.035 & 1.762 & 0.656 & -1.067 & 0.536 & 0.796 & 0.562 & 0.491 \\
\hline Raggedness index & 0.728 & 0.166 & 0.205 & 0.243 & 0.728 & 0.166 & 0.705 & 0.605 & 0.167 & 0.201 & 0.267 & 0.243 \\
\hline \multicolumn{13}{|l|}{ DTHK } \\
\hline FS & $3.4^{*} 10^{38}$ & -1.502 & -1.984 & -0.183 & $3.4^{*} 10^{38}$ & -1.502 & 0.468 & -0.402 & -0.513 & 5.718 & 0 & -0.183 \\
\hline Raggedness index & 0 & 0.393 & 0.306 & 0.201 & 0 & 0.393 & 0.355 & 0.658 & 0.165 & 0.505 & 0 & 0.201 \\
\hline \multicolumn{13}{|l|}{ B) A. schaueriana } \\
\hline ITS & \multicolumn{2}{|c|}{ model As1 } & \multicolumn{5}{|c|}{ model As6 } & & & & & \\
\hline Statistics & AsNBr & $\mathrm{AsSBr}$ & PAR & ALC_PRC & VER & GPM_PPR_UBA_CNN & FLN & & & & & \\
\hline Tajima's D & -2.721 & -2.398 & -2.804 & -2.233 & -3.094 & -2.345 & 0 & & & & & \\
\hline$D^{*}$ & 0.543 & 0.477 & 1.315 & -0.990 & 0.755 & 1.751 & 0 & & & & & \\
\hline$F^{*}$ & -0.264 & 0.511 & 0.643 & -0.650 & 0.362 & 1.839 & 0 & & & & & \\
\hline Raggedness index & 0.780 & 0.534 & 0.498 & 0 & 0 & 0.467 & 0 & & & & & \\
\hline \multicolumn{13}{|l|}{ DTHK } \\
\hline FS & -8.218 & -11.061 & -3.382 & 0 & -3.642 & -3.637 & -1.250 & & & & & \\
\hline Raggedness index & 0.253 & 0.680 & 0.043 & 0 & 0.339 & 0.835 & 0.459 & & & & & \\
\hline
\end{tabular}

Results of tests for neutrality and population expansion given two different evolutionary scenarios for A) A. germinans and B) $A$. schaueriana based on microsatellite, cpDNA and nDNA markers. The values of Tajima's D (Tajima, 1989); Fu and Li's D* and F*(Fu \& Li, 1993); the raggedness index (Rogers \& Harpending, 1992); and Fu's FS (Fu, 1997) are shown. The values in italics indicate $P<0.02$ for $F S$ and $P<0.05$ for the remaining statistics.

support the asymmetrical hybridization between these species, indicating that gene flow may indeed occur bidirectionally.

These observations suggest that introgressive hybridization is a more widespread process on both coasts of the American continent for Avicennia than previously believed, adding a relevant report to the large list of examples of hybridization in mangrove species. Based on the morphological and molecular data, interspecific gene flow has been described for the genera Rhizophora, Bruguiera (Rhizophoraceae), Sonneratia (Lythraceae), Lumnitzera (Combretaceae) and Avicennia [1,23,52-57]. Although we can speculate on the mechanisms that maintain the widespread breeding between related mangrove species and on the evolutionary consequences of this process, we prefer to encourage further genetic and ecological studies regarding these intriguing questions.

Geographic distribution of intraspecific genetic diversity At the species level, A. bicolor, A. germinans and A. schaueriana presented clear genetic differentiation despite the evidence for introgression previously discussed here and elsewhere [23]. Conversely, at the intraspecific level, the organization of the genetic variation in A. germinans and $A$. schaueriana was not obvious.

The Pacific and Atlantic samples of A. germinans clearly clustered into different groups. The samples from the west coast of Central America were mostly phylogenetically separate from the remaining haplotypes, which can be readily visualized in ITS and DTHK haplotype networks (Figure 2). However, for the chloroplast marker (Figure 2A), there was haplotype sharing between samples from the Pacific coast of Mexico and from the Atlantic coast of the American continent. This distribution is most likely explained by intraspecific ancestral polymorphism because of the low frequency of the shared haplotype (Figure 2B) and because the Isthmus of Panama is a strong barrier to pollen flow for this insectpollinated species [25]. Another explanation for this sharing is that past sea-level fluctuations may have facilitated pollen gene flow, as has been proposed for Hibiscus pernambucensis Arruda (Malvaceae) [58], whose pollination is also based on insects. In total, despite the evident Pacific-Atlantic differentiation [18,23,25,40], the evolutionary scenario in the Atlantic basin, where our sampling size was larger, is complex.

Individuals from both sides of the Atlantic Ocean shared ITS and DTHK haplotypes, and those haplotypes that were different were phylogenetically closely related (Figures 2); this observation has already been reported using the same set of markers [23] and PCR-restriction fragment length polymorphism coupled with chloroplast microsatellites [18]. The new results that we present in this study indicate that the LDD between Africa and 
America is a more common process than previously thought, corroborating the previous rejection of a vicariant process to explain the widespread distribution of $A$. germinans [18]. Despite the drawbacks of the use of ITS for genus and species level evolutionary studies such as homoplasy, loci duplication and contamination due to its universality $[59,60]$, we argue that the ITS haplotype sharing we observed is valid but not stand-alone evidence of A. germinans transatlantic seed dispersal.

This finding supports and extends the role of transatlantic dispersal as a relevant evolutionary process for the mangrove species A. germinans [18] and R. mangle [20], whose propagules may float, survive and even produce roots after long periods in fresh and salt water [61]. Moreover, LDD across the Atlantic Ocean has also been reported for Hibiscus L., a sea-dispersed plant, [58,62] and even for a species whose seeds have no adaptations for water dispersal [63]. This movement between the west coast of Africa and the east coast of South America is most likely driven by the high surface velocity of the westward southern South Equatorial Current (SEC) [64].

Interestingly, despite the high longevity of $A$. germinans propagules in salt and fresh water and their high buoyancy (A. germinans propagules always float, even when rotten) [61], LDD is likely not a relatively frequent process for this species. This mechanism is likely to be rare enough that there is no generalized homogenization of the species genetic diversity [26]. We have previously reported that there was genetic structure on different geographic scales along the Brazilian coast, with significant genetic differentiation between samples separated by distances from thousands of kilometers to hundreds of meters, regarding microsatellite analyses in both A. germinans and A. schaueriana [26]. Moreover, limitations of gene flow, even within estuaries, have been reported in Central America for A. germinans and $R$. mangle [25]. The observation of both long-distance dispersal and limited dispersal was also observed for mangrove species from the Eastern Hemisphere, e.g., Rhizophora [65,66], Ceriops (Rhizophoraceae) [67-69] and Kandelia (Rhizophoraceae) [70-72] species. Whether this pattern of limited and, intriguingly, long-distance dispersal is a general feature of mangrove biology remains to be tested.

An evaluation of DTHK and ITS markers supports these results; in this study, we observed that, although there was considerable haplotype sharing among the $A$. germinans samples, there was also generally substantial and significant genetic differentiation, as measured by global $\mathrm{G}_{\mathrm{ST}}$, its comparison with $\mathrm{N}_{\mathrm{ST}}$ and the pairwise $\Phi_{\text {ST }}$ (see Additional file 2) with a complex pattern in the MDS plot (Figure 3A). The most robust hypothesis of genetic organization by the hierarchical AMOVA corroborates these results because the most reliable hypothesis was generated by considering each of the samples separately (Table 2), supporting the pattern that explains small geographic scale structure using microsatellites [26]. This result indicates that the historical and current propagule dispersal of $A$. germinans is limited and usually occurs locally; for example, dispersal may occur in a forest continuum, such as the AMMC, or within a single estuary, such as in Central America [25].

In A. schaueriana, there was also a complex relationship between the genealogical inferences and the geographic distribution of haplotypes. Many of the haplotypes were shared by different and geographically distant samples (Figure 2), and we similarly observed a high level of genetic structure, as revealed by global $G_{\text {ST }}$ measures. Despite the notable differences between the DTHK and ITS results regarding the pairwise $\Phi_{\mathrm{ST}}$ (see Additional file 2), which are easily observed in the MDS plot (Figure 3B), one a posteriori grouping was consistently supported by both markers when we considered the hierarchical AMOVA outcomes (Table 2). The As6 model differed slightly from the models that examined small-scale genetic structure using microsatellites [26] and the tested a priori groupings (models As8 and As9 - Table 2), and it could explain the nonsignificant difference between $\mathrm{N}_{\mathrm{ST}}$ and $\mathrm{G}_{\mathrm{ST}}$ from the PERMUT analysis for A. schaueriana. The samples from this species are probably not from independent populations, in contrast to what we observed for A. germinans. The relatively low variance among groups (46.97\%) for the DTHK marker may be explained by the remarkable genetic diversity of this marker that was observed in AsPAR compared to other A. schaueriana samples (Table 2); this diversity produced a large proportion of the molecular variability within the samples (54.16\%).

As a whole, the most likely groupings hypothesized herein disagree with the most feasible evolutionary scenarios inferred by means of microsatellite data in $A$. germinans and A. schaueriana [26] and other seadispersed plants, including $R$. mangle $[17,20]$ and $H$. pernambucensis [58]. For all of these species, a similar pattern of genetic structure was observed, with a clear distinction between the samples that were collected from sites north and south of the northeastern extremity of Brazil (Figure 1). Models Ag4 and As1 rely on this pattern of genetic structure and poorly explained the molecular variation we observed (Table 2). This finding indicates that there are, most likely, different historical and ongoing processes influencing the genetic diversity of these Avicennia species due to the differences in the mutation rates between these sequence-based markers and microsatellites [73-75].

\section{Historical and ecological processes shape the genetic diversity of $A$. germinans and $A$. schaueriana}

The line of reasoning mentioned above supports the hypothesis that Avicennia has been affected by historical 
demographic changes in the ACEP region (more precisely, in the Pacific basin of Central America $[18,19]$ and more broadly in the Eastern Hemisphere [76]). During glacial periods, high-latitude edge populations would have become extinct and would subsequently have been recolonized by individuals from core regions near the Equator [18,76]. The A. germinans and A. schaueriana samples in this study did not indicate a higher genetic diversity poleward by means of either the DTHK or ITS markers (Table 1) or by microsatellites [26]. However, the disagreement between the most likely scenarios considering high (Ag4 and As1) and low mutation rates indicates that different processes have shaped and continue to influence the species' genetic diversity. We argue that a similar process most likely occurred along the Atlantic coast of South America.

After extinction events occurred due to Quaternary environmental changes, populations would have become more isolated [77]. This disjoint distribution, coupled with the limited gene flow caused by relatively restricted pollen and propagule dispersal, would have enabled the evolution of distinct independent lineages that could later expand their geographic distribution after the glaciation. This evolutionary scenario explains the shared haplotypes between our studied samples and the genealogical relationships of the ITS marker (Figure 2A), which were observed in samples from three sites separated by hundreds of kilometers. This scenario is also consistent with the partial incongruence between the sequence-based and microsatellite genetic structures. To further test this hypothesis, we studied the eventual demographic expansion signals. If this evolutionary history is consistent, we would expect to observe significant evidence of demographic expansion across the inferred populations.

For both species, we tested whether the groupings that yielded the most likely genetic structure pattern with regard to microsatellite and sequence-based marker results (regarding models As1 and As6 for A. schaueriana and model Ag1 and considering each sample separately for A. germinans) presented signs of recent demographic change. For both species, in aggregate, we found signs of population growth for different evolutionary scenarios across the samples (Table 3). Contrary to our expectations, we found no signs of demographic expansion in the samples from the Pacific basin of southern Central America, which was presumably a refugium during the last glaciation $[18,19]$; instead, we observed indications of background selection in these samples. In the South American Atlantic basin, we found that A. germinans and $A$. schaueriana most likely responded differently to the post-glacial period. Whereas A. germinans only showed evidence of population growth on the northern coast of Brazil (model Ag1, and in AgMRJ, AgPAa and AgPAb when each sample was evaluated), there were consistent indications that recent demographic expansion occurred along the entire A. schaueriana distribution regardless of the model that was assumed (Table 3 ).

The differences between the patterns of recent population growth explains the current geographic distribution of these species along the Atlantic Coast of South America (Figure 1) because we found more substantial signs of demographic expansion (with evidence from both DTHK and ITS) in a broader geographic extension for $A$. schaueriana than for A. germinans. We argue that because the southern limit of the A. schaueriana distribution presents temperatures within the range of variation of $A$. germinans [4] and because this climatic factor is regarded as a major driver that influences mangrove latitudinal limits [3], additional major traits must influence the distributions of these species in South America. This pattern of geographic distribution may have been originated by an ecological difference between these species; the unequal historical effectiveness of relative gene flow may have resulted from pollen and propagule dispersal. A. germinans pollen and propagules contributed similarly to the gene flow; however, in A. schaueriana, we observed that gene flow via sea-water dispersed propagules was one to two times higher than gene flow via pollen along the Brazilian coast. This difference may imply a more efficient dispersal that could have enabled $A$. schaueriana to colonize the southern and southeastern coast of Brazil. These inferences of past pollen to seed gene flow are similar to those observed for A. germinans from the Pacific and Atlantic basins of Panama, with $r=-0.64$ [25]; however, because different sets of molecular markers were used, direct comparisons between these studies are not possible.

\section{Conclusions}

The Avicennia species from the ACEP region presented genetic structuring at different levels of organization. $A$. bicolor, A. germinans and A. schaueriana are distinct evolutionary lineages whose boundaries are not complete because there is evidence for past [23] and ongoing introgressive hybridization processes on the American continent. Given the intraspecific level, in addition to finding new evidence of transatlantic LDD of A. germinans that may contribute to its widespread distribution within the South American Atlantic basin, we observed partially discordant molecular variation patterns between high (microsatellites - [26]) and low (DTHK and ITS present work) mutation rate markers for both $A$. germinans and $A$. schaueriana. We argue that this discordance is likely due to a recent demographic expansion of both species, whose patterns diverge between these species. This disagreement, coupled with a larger proportion of gene flow brought by propagules rather than pollen in $A$. schaueriana but not in A. germinans, explains the current distribution of these species in South America. 
In addition to these retrospective conclusions, the novel details that our findings revealed about the evolutionary history of the ACEP region Avicennia species can also provide valuable information about the responses of these plants to current global climate change. For example, despite their close phylogenetic relationship, A. germinans and A. schaueriana have responded differently since the last glaciation, and it is, thus, likely that their distinct ecological features may also influence their future in the face of the currently changing world. Considering this information about the past, our current endeavor is to understand potential impacts of the current climate changes on the neutral genetic variation of A. germinans and A. schaueriana.

\section{Additional files}

Additional file 1: Avicennia samples analyzed in this study. Taxa, collection codes with sample sizes within parentheses for samples we collected, locations (degree decimals and geopolitical units) and geographic regions (with abbreviations in parentheses) of the samples evaluated using ITS (nDNA), trnD-trnT and trnH (cpDNA) markers.

Additional file 2: Intraspecific pairwise genetic structure for $A$. germinans and $A$. schaueriana. Pairwise $\Phi_{S T}$ between samples of A) A. germinans and B) A. schaueriana. The values below the diagonal were obtained using the ITS marker, and the values above the diagonal were obtained using the DTHK marker. The bold and underlined numbers indicate the nonsignificant pairwise $\Phi_{\mathrm{ST}}$ values after 10,000 bootstraps.

\section{Competing interests}

The authors declare that they have no competing interests.

\section{Authors' contributions}

GMM conceived and designed this study, collected materials, performed experiments, analyzed the data and wrote the paper with the assistance of MIZ and APS. MIZ contributed to data analyses. IS provided field support. APS, IS and MIZ conceived the study and participated in its design and coordination. All authors read, reviewed and approved the final manuscript.

\section{Acknowledgments}

The work was supported by Fundação de Amparo à Pesquisa de São Paulo (FAPESP) to GMM (graduate fellowships 2007/57021-9, 2010/50033-4 and Post-Doctoral fellowship 2013/08086-1) and APS (research grants 2008/52045-0 and 2010/50178-2) and by the Conselho Nacional de Desenvolvimento Científico e Tecnológico (CNPq) for research fellowships to APS, IS and MIZ. The authors also thank U. Mehlig and I. C. Menezes for sampling support and assistance in the field.

\section{Author details}

${ }^{1}$ Centro de Biologia Molecular e Engenharia Genética, Universidade Estadual de Campinas, CEP 13083-875, CP 6010 Campinas, São Paulo, Brazil. ²ólo Centro Sul, Agência Paulista de Tecnologia dos Agronegócios. Piracicaba, CEP 13400-970, São Paulo, Brazil. ${ }^{3}$ Universidade Federal do Pará, Campus de Bragança, Instituto de Estudos Costeiros, CEP 68600-000, Bragança, Pará, Brazil. ${ }^{4}$ Departamento de Biologia Vegetal, Instituto de Biologia, Universidade Estadual de Campinas, CEP 13083-862, Campinas, São Paulo, Brazil.

Received: 7 October 2014 Accepted: 30 March 2015

Published online: 10 April 2015

\section{References}

1. Tomlinson PB. The botany of mangroves. 1st ed. Cambridge, MA: Cambridge University Press; 1986. p. 419.
2. Pickens $\mathrm{CN}$, Hester MW. Temperature tolerance of early life history stages of black mangrove Avicennia germinans: implications for range expansion. Estuaries and Coasts. 2010;34:824-30.

3. Duke NC, Ball MC, Ellison JC. Factors influencing biodiversity and distributional gradients in mangroves. Glob Ecol Biogeogr Lett. 1998;7:27-47.

4. Quisthoudt K, Schmitz N, Randin CF, Dahdouh-Guebas F, Robert EMR, Koedam $\mathrm{N}$. Temperature variation among mangrove latitudinal range limits worldwide. Trees. 2012;26:1919-31.

5. Saintilan N, Wilson NC, Rogers K, Rajkaran A, Krauss KW. Mangrove expansion and salt marsh decline at mangrove poleward limits. Glob Chang Biol. 2014;20:147-57.

6. Mckee KL, Rogers K, Saintilan N. Response of salt marsh and mangrove wetlands to changes in atmospheric $\mathrm{CO}_{2}$, climate, and sea level. In: Middleton BA, editor. Global change and the function and distribution of wetlands. First. Dordrecht: Springer Netherlands; 2012. p. 63-96.

7. Comeaux RS, Allison MA, Bianchi TS. Mangrove expansion in the Gulf of Mexico with climate change: Implications for wetland health and resistance to rising sea levels. Estuar Coast Shelf Sci. 2012;96:81-95.

8. Osland MJ, Enwright N, Day RH, Doyle TW. Winter climate change and coastal wetland foundation species: salt marshes vs. mangrove forests in the southeastern United States. Glob Chang Biol. 2013;19:1482-94.

9. Perry CL, Mendelssohn IA. Ecosystem effects of expanding populations of Avicennia germinans in a Louisiana salt marsh. Wetlands. 2009;29:396-406.

10. Soares MLG, Estrada GCD, Fernandez V, Tognella MMP. Southern limit of the Western South Atlantic mangroves: assessment of the potential effects of global warming from a biogeographical perspective. Estuar Coast Shelf Sci. 2012;101:44-53.

11. Adams JB, Colloty BM, Bate GC. The distribution and state of mangroves along the coast of Transkei, Eastern Cape Province, South Africa. Wetlands Ecol Manage. 2004;12:531-41.

12. Stokes DJ, Healy TR, Cooke PJ. Expansion dynamics of monospecific, temperate mangroves and sedimentation in two embayments of a barrier-enclosed lagoon, Tauranga Harbour, New Zealand. J Coastal Res. 2010;261:113-22.

13. Lovelock CE, Feller IC, Ellis J, Schwarz AM, Hancock N, Nichols P, et al. Mangrove growth in New Zealand estuaries: the role of nutrient enrichment at sites with contrasting rates of sedimentation. Oecologia. 2007;153:633-41.

14. Saintilan N, Williams RJ. Mangrove transgression into saltmarsh environments in South-East Australia. Glob Ecol Biogeogr. 1999;8:1999.

15. Ellison J. Pollen evidence of Late Holocene mangrove development in Bermuda. Glob Ecol Biogeogr Lett. 1996;5:315-26.

16. Ellison JC. Long-term retrospection on mangrove development using sediment cores and pollen analysis: a review. Aquat Bot. 2008;89:93-104

17. Pil MW, Boeger MRT, Muschner VC, Pie MR, Ostrensky A, Boeger W. Postglacial north-south expansion of populations of Rhizophora mangle (Rhizophoraceae) along the Brazilian coast revealed by microsatellite analysis. Am J Bot. 2011;98:1031-9.

18. Nettel A, Dodd RS. Drifting propagules and receding swamps: genetic footprints of mangrove recolonization and dispersal along tropical coasts. Evolution. 2007;61:958-71.

19. Sandoval-Castro E, Dodd RS, Riosmena-Rodríguez R, Enríquez-Paredes LM, Tovilla-Hernández C, López-Vivas JM, et al. Post-glacial expansion and population genetic divergence of mangrove species Avicennia germinans ( $L$.) Stearn and Rhizophora mangle L. along the Mexican coast. PLoS One. 2014;9:e93358.

20. Takayama K, Tamura M, Tateishi Y, Webb EL, Kajita T. Strong genetic structure over the American continents and transoceanic dispersal in the mangrove genus Rhizophora (Rhizophoraceae) revealed by broad-scale nuclear and chloroplast DNA analysis. Am J Bot. 2013;100:1-11.

21. Schaeffer-Novelli Y, Cintrón-Molero G, Adaime RR, De Camargo TM, De Camargo TM. Variability of mangrove ecosystems along the Brazilian coast. Estuaries. 1990;13:204-18.

22. Spalding M, Kainuma M, Collins L. World atlas of mangroves. 2nd ed. London: Earthscan; 2010. p. 319 
23. Nettel A, Dodd RS, Afzal-Rafii Z, Tovilla-Hernández C. Genetic diversity enhanced by ancient introgression and secondary contact in East Pacific black mangroves. Mol Ecol. 2008;17:2680-90.

24. Nettel A, Dodd RS, Ochoa-Zavala M, Tovilla-Hernández C, Días-Gallegos JR. Mating system analyses of tropical populations of the black mangrove Avicennia germinans (L.) L. (Avicenniaceae). Bot Sci. 2013;91:115-7.

25. Cerón-Souza I, Bermingham E, McMillan WO, Jones FA. Comparative genetic structure of two mangrove species in Caribbean and Pacific estuaries of Panama. BMC Evol Biol. 2012;12:205.

26. Mori GM, Zucchi MI, Souza AP. Multiple-geographic-scale genetic structure of two mangrove tree species: the roles of mating system, hybridization, limited dispersal and extrinsic factors. PLoS One. 2015;10:1-23.

27. Demesure B, Sodzi N, Petit RJ. A set of universal primers for amplification of polymorphic non-coding regions of mitochondrial and chloroplast DNA in plants. Mol Ecol. 1995;4:129-31.

28. White TT, Bruns T, Lee S, Taylor J. Amplification and direct sequencing of fungal ribosomal RNA genes for phylogenetics. In: Innis MA, Gelfand DH, Sninsky JJ, White TJ, editors. PCR protocols: a guide to methods and applications. Academic P. San Diego: Academic Press; 1990. p. 315-22

29. Edgar RC. MUSCLE: A multiple sequence alignment method with reduced time and space complexity. BMC Bioinformatics. 2004;5:113.

30. Stephens M, Smith NJ, Donnelly P. A new statistical method for haplotype reconstruction from population data. Am J Hum Genet. 2001;68:978-89.

31. Bandelt HJ, Forster P, Röhl A. Median-joining networks for inferring intraspecific phylogenies. Mol Biol Evol. 1999;16:37-48.

32. Leigh J, Bryant D, Steel M. PopART. 2014

33. Excoffier $L$, Lischer HEL. Arlequin suite ver 3.5: a new series of programs to perform population genetics analyses under Linux and Windows. Mol Ecol Resour. 2010;10:564-7.

34. R Core Team C. R: A language and environment for statistical computing. 2013

35. Wright S. Isolation by distance. Genetics. 1943;28:114-38.

36. Nei M. Analysis of gene diversity in subdivided populations. Proc Natl Acad Sci. 1973:70:3321-3.

37. Librado P, Rozas J. DnaSP v5: a software for comprehensive analysis of DNA polymorphism data. Bioinformatics. 2009:25:1451-2.

38. Ennos RA. Estimating the relative rates of pollen and seed migration among plant populations. Heredity. 1994;72:250-9.

39. Excoffier L, Smouse P, Quattro J. Analysis of molecular variance inferred from metric distances among DNA haplotypes: application to human mitochondrial DNA restriction data. Genetics. 1992;131:479-91.

40. Dodd RS, Afzal-Rafii Z, Kashani N, Budrick J. Land barriers and open oceans: effects on gene diversity and population structure in Avicennia germinans L. (Avicenniaceae). Mol Ecol. 2002;11:1327-38.

41. Nascimento WR, Souza-Filho PWM, Proisy C, Lucas RM, Rosenqvist A. Mapping changes in the largest continuous Amazonian mangrove belt using object-based classification of multisensor satellite imagery. Estuar Coast Shelf Sci. 2013:117:83-93.

42. Pons $\mathrm{O}$, Petit RJ. Measuring and testing genetic differentiation with ordered versus unordered alleles. Genetics. 1996;144:1237-45.

43. Tajima F. Statistical method for testing the neutral mutation hypothesis by DNA polymorphism. Genetics. 1989;595:585-95.

44. Fu Y-X. Statistical tests of neutrality of mutations against population growth, hitchhiking and background selection. Genetics. 1997;147:915-25.

45. Fu Y-X, Li W-H. Statistical tests of neutrality of mutations. Genetics. 1993;133:693-709.

46. Ramírez-Soriano A, Ramos-Onsins SE, Rozas J, Calafell F, Navarro A. Statistical power analysis of neutrality tests under demographic expansions, contractions and bottlenecks with recombination. Genetics. 2008;179:555-67.

47. Rogers AR, Harpending $H$. Population growth makes waves in the distribution of pairwise genetic differences. Mol Biol Evol. 1992;9:552-69.

48. Ramos-Onsins SE, Rozas J. Statistical properties of new neutrality tests against population growth. Mol Biol Evol. 2002;19:2092-100.

49. Slatkin M, Hudson RR. Pairwise comparisons of mitochondrial DNA sequences in stable and exponentially growing populations. Genetics. 1991;562:555-62

50. Rannala B. Gene genealogy in a population of variable size. Heredity. 1997;78:417-23.

51. Rosenberg NA, Hirsh AE. On the use of star-shaped genealogies in inference of coalescence times. Genetics. 2003;1682:1677-82.
52. Cerón-Souza I, Rivera-Ocasio E, Medina E, Jiménez JA, McMillan WO, Bermingham E. Hybridization and introgression in New World red mangroves, Rhizophora (Rhizophoraceae). Am J Bot. 2010;97:945-57.

53. Sun M, Lo EYY. Genomic markers reveal introgressive hybridization in the Indo-West Pacific mangroves: a case study. PLoS One. 2011;6:e19671.

54. Qiu S, Zhou R, Li Y, Havanond S. Molecular evidence for natural hybridization between Sonneratia alba and S. griffithii. J Syst Evol. 2008:46:391-5.

55. Zhou R, Gong X, Boufford D, Wu C-1, Shi S. Testing a hypothesis of unidirectional hybridization in plants: observations on Sonneratia, Bruquiera and Ligularia. BMC Evol Biol. 2008;8:149.

56. Guo M, Zhou R, Huang Y, Ouyang J, Shi S. Molecular confirmation of natural hybridization between Lumnitzera racemosa and Lumnitzera littorea. Aquat Bot. 2011;95:59-64

57. Duke NC. Overlap of eastern and western mangroves in the South-western Pacific: hybridization of all three Rhizophora (Rhizophoraceae) combinations in New Caledonia. Blumea Biodivers Evol Biogeography Plants. 2010;55:171-88.

58. Takayama K, Tateishi Y, Murata J, Kajita T. Gene flow and population subdivision in a pantropical plant with sea-drifted seeds Hibiscus tiliaceus and its allied species: evidence from microsatellite analyses. Mol Ecol. 2008;17:2730-42

59. Álvarez I, Wendel JF. Ribosomal ITS sequences and plant phylogenetic inference. Mol Phylogenet Evol. 2003;29:417-34.

60. Nieto Feliner G, Rosselló JA. Better the devil you know? Guidelines for insightful utilization of nrDNA ITS in species-level evolutionary studies in plants. Mol Phylogenet Evol. 2007:44:911-9.

61. Rabinowitz D. Dispersal properties of mangrove propagules. Biotropica 1978:10:47-57.

62. Takayama K, Kajita T, Murata J, Tateishi Y. Phylogeography and genetic structure of Hibiscus tiliaceus-speciation of a pantropical plant with sea-drifted seeds. Mol Ecol. 2006;15:2871-81.

63. Dick CW, Bermingham E, Lemes MR, Gribel R. Extreme long-distance dispersal of the lowland tropical rainforest tree Ceiba pentandra L. (Malvaceae) in Africa and the Neotropics. Mol Ecol. 2007;16:3039-49.

64. Lumpkin R, Johnson GC. Global ocean surface velocities from drifters: Mean, variance, El Niño-Southern Oscillation response, and seasonal cycle. J Geophysical Res Oceans. 2013;118:2992-3006.

65. Islam MS, Lian C, Kameyama N, Hogetsu T. Low genetic diversity and limited gene flow in a dominant mangrove tree species (Rhizophora stylosa) at its northern biogeographical limit across the chain of three Sakishima islands of the Japanese archipelago as revealed by chloroplast and nuclear SSR analysis. Plant Syst Evol. 2014;300:1123-36.

66. Lo EYY, Duke NC, Sun M. Phylogeographic pattern of Rhizophora (Rhizophoraceae) reveals the importance of both vicariance and long-distance oceanic dispersal to modern mangrove distribution. BMC Evol Biol. 2014;14:83.

67. McGuinness KA. Dispersal, establishment and survival of Ceriops tagal propagules in a north Australian mangrove forest. Oecologia. 1996;109:80-7.

68. Liao P-C, Hwang S-Y, Huang S, Chiang Y-C, Wang J-C. Contrasting demographic patterns of Ceriops tagal (Rhizophoraceae) populations in the South China Sea. Aust J Bot. 2011:59:523.

69. Liao PC, Chiang YC, Huang S, Wang JC. Gene flow of Ceriops Tagal (Rhizophoraceae) across the kra isthmus in the thai malay peninsula. Bot Stud. 2009:50:193-204.

70. Geng Q, Lian C, Goto S, Tao J, Kimura M, Islam MS, et al. Mating system, pollen and propagule dispersal, and spatial genetic structure in a high-density population of the mangrove tree Kandelia candel. Mol Ecol. 2008;17:4724-39.

71. Chiang TY, Chiang YC, Chen YJ, Chou CH, Havanond S, Hong TN, et al. Phylogeography of Kandelia candel in East Asiatic mangroves based on nucleotide variation of chloroplast and mitochondrial DNAs. Mol Ecol. 2001;10:2697-710.

72. Islam MS, Lian C, Kameyama N, Hogetsu T. Analyses of genetic population structure of two ecologically important mangrove tree species, Bruquiera gymnorrhiza and Kandelia obovata from different river basins of Iriomote Island of the Ryukyu Archipelago, Japan. Tree Genet Genomes. 2012:8:1247-60.

73. Wang IJ. Recognizing the temporal distinctions between landscape genetics and phylogeography. Mol Ecol. 2010;19:2605-8.

74. Anderson CD, Epperson BK, Fortin M-J, Holderegger R, James PMA, Rosenberg MS, et al. Considering spatial and temporal scale in landscape-genetic studies of gene flow. Mol Ecol. 2010;19:3565-75. 
75. Sunnucks P. Efficient genetic markers for population biology. Trends Ecol Evol. 2000;15:199-203.

76. Arnaud-Haond S, Teixeira S, Massa SI, Billot C, Saenger P, Coupland G, et al. Genetic structure at range edge: low diversity and high inbreeding in Southeast Asian mangrove (Avicennia marina) populations. Mol Ecol. 2006;15:3515-25.

77. Woodroffe CD, Grindrod J. Mangrove biogeography : the role of Quaternary environmental and sea-level change. J Biogeogr. 1991;18:479-92.

Submit your next manuscript to BioMed Central and take full advantage of:

- Convenient online submission

- Thorough peer review

- No space constraints or color figure charges

- Immediate publication on acceptance

- Inclusion in PubMed, CAS, Scopus and Google Scholar

- Research which is freely available for redistribution 